Volume 8. No. 9, September 2020

International Journal of Emerging Trends in Engineering Research

Available Online at http://www.warse.org/IJETER/static/pdf/file/ijeter35892020.pdf https://doi.org/10.30534/ijeter/2020/35892020

\title{
On The Simulation of Beck Column through a Simple Xiong-Wang-Tabarrok Experimental Model of Centripetally Loaded Column
}

\author{
J. Peter Praveen ${ }^{1}$, B. Nageswara Rao ${ }^{2}$, B.Mahaboob ${ }^{3}$, M.Rajaiah ${ }^{4}$, Y.Harnath ${ }^{5}$, C.Narayana ${ }^{6}$ \\ ${ }^{1}$ Department of Mathematics, Koneru Lakshmaiah Education Foundation, Vaddeswaram, Guntur, India-522502, \\ jppraveen17@kluniversity.in \\ ${ }^{2}$ Department of Mechanical Engineering, Koneru Lakshmaiah Education Foundation, Vaddeswaram, Guntur, India-522502, \\ bnrao52@rediffmail.com \\ ${ }^{3}$ Department of Mathematics, Koneru Lakshmaiah Education Foundation, Vaddeswaram, Guntur, India-522502, \\ mahaboob@kluniversity.in \\ ${ }^{4}$ Department of Mathematics, Audisankara College of Engineering \&Technology (Autonomous), Gudur, SPSR Nellore,A.P,- \\ 524101, rajagopal1402@gmail.com \\ ${ }^{5}$ Department of Mathematics, Audisankara College of Engineering \& Technology (Autonomous), Gudur, SPSR Nellore,A.P,- \\ 524101, harnath.yeddala@gmail.com \\ ${ }^{6}$ Department of Mathematics, Sri Harsha Institute of P.G Studies,Nellore,A.P,-524101, nareva.nlr@gmail.com
}

\begin{abstract}
The controversial articles authored by Koiter and by Sugiyama, Langthjem and Ryu on unrealistic and realistic follower forces indicate the complexity in experimental verification. Elishakoff has made a review on various testing procedures creating the follower force. Xiong, Wang and Tabarrok have proposed a simple experimental model of centripetally loaded column simulating the Beck column. They have not conducted experiments up to the initiation of instability. They have employed a curvefitting procedure for the measured data relevant to the load parameter and the frequency parameter. The estimated stability load of Beck's column from the fitted curve is below $10 \%$ of the theoretical value. They have analyzed the dynamic characteristics of Beck column and a centripetally loaded column for showing the equivalence of a frequency and the corresponding mode. This article demonstrates their equivalence directly from the dynamic characteristics of Beck column. The discrepancy between dynamic analysis results and test data (if any) can be due to the assigned values of the Young's modulus and mass density of the material. The characteristic equation of Beck's column should not be modified to account the discrepancies as being done by Xiong, Wang and Tabarrok, whose experiments are partially successful.
\end{abstract}

Key words: Beck column, tip-concentrated tangential load, tip-angle, critical load parameter, frequency parameter, coalescence frequency parameter.

\section{INTRODUCTION}

Dynamic stability of elastic structures is a fascinating topic. After Beck in 1952, many researchers have examined theoretically considering a cantilever column under a tip-concentrated tangential load (the so-called Beck column) [1-13]. The column stability is assessed by generating the load versus frequency curve, namely the eigencurve. Timoshenko and Gere [1] have emphasized experimental verification. Willems [14] has adopted a simple procedure to perform experiments, whose validity is discussed by Huang et al. [15] and other Professors (Augusti, Levinson, Roorda and Herrmann) [16]. The controversial articles of Koiter [17] and Sugiyama et al. [18] on unrealistic and realistic follower forces remains a matter of debate [19]. The basic problem is in the practical realization of follower forces [20, 21]. Mullagulov [22] has created follower forces and tested several hardened steel cantilever rods. Elishakoff [6] has made a review on various testing procedures creating the follower force. Sugiyama et al. [23-25] have conducted experiments by mounting a solid rocket motor at a freeend of the cantilever column to generate a tipconcentrated sub-tangential follower force. Their test results cannot be utilized directly for comparison of critical load estimates [26]. Xiong- Wang-Tabarrok experimental model of centripetally loaded column simulates the Beck column [27]. In order to demonstrate the equivalence of a frequency and the corresponding mode, they have analyzed the dynamic characteristics of Beck column and a centripetally loaded column. This article presents a simple mathematical formulation to show their equivalence directly from the dynamic characteristics of Beck column.

\section{MATHEMATICAL FORMULATION}

Figure 1 shows a cantilever column under a tipconcentrated follower load $(P)$ having tip-angle $\phi(0)$, the deformed coordinates $(X, Y)=\int_{s}^{L}(\cos \phi, \sin \phi) d s$, and the tip-coordinates $\left(X_{a}, Y_{a}\right)$ at $s=0$. ' $s$ ' is the length of the deflection curve measured from the tip. $\mathrm{OB}=L$, is the column length. $m$ is the mass per unit length of the column. $\phi(s)$ is the angle between the tangent to the deformed column and its vertical axis. $\mathrm{BQ}=$ $\delta$, is the distance from the tip (B) of the un-deformed column to the point $(\mathrm{Q})$ where the tangent line AQ at the free end of the deformed column intersects the column 
axis $\mathrm{OB}$ at $\mathrm{Q}$. Denoting $E$ and $I$ as the Young's modulus and the moment of inertia respectively, Mutyalarao et al. $[13,26]$ have presented a system of nonlinear differential equations assuming harmonic motion for large deflections of a cantilever column based on the moment $(M)$ curvature $\left(\rho^{-1}\right)$ relationship. They have defined $x=\frac{X}{L}$; $y=\frac{Y}{L} ; \quad \eta=\frac{s}{L} ; \lambda=\frac{P L^{2}}{E I}$, is the load parameter; $\omega=\Omega L^{2} \sqrt{\frac{m}{E I}}$, is the frequency parameter;

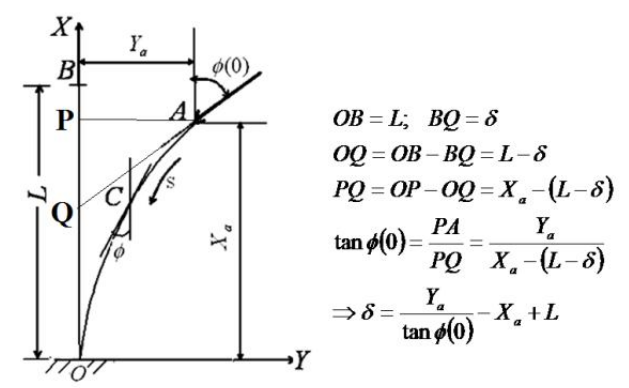

Figure 1: Deformation of a cantilever column under a tipconcentrated follower load $(P)$ having tip-angle $\phi(0)$.

In case of small deflections (i.e., $\phi \rightarrow 0$ ), $\cos \phi \approx 1$ and $\sin \phi \approx \phi . \quad X(s)=L-s \Rightarrow X_{a}=L \quad$ and $\frac{\delta}{L}=\frac{Y_{a}}{L \phi(0)}=\frac{y_{a}}{\phi(0)}$. Further, defining $\tilde{y}=\frac{y}{\phi(0)}$, the nonlinear differential equations (9) to (15) of Refs. [13, 26] are reduced to

$\tilde{y}^{i v}+\lambda \tilde{y}^{\prime \prime}-\omega^{2} \tilde{y}=0$

The boundary conditions are

$$
\begin{aligned}
& \tilde{y}^{\prime}=-1, \tilde{y}^{\prime \prime}=\tilde{y}^{\prime \prime \prime}=0 \quad \text { at } \eta=0 \\
& \tilde{y}=\tilde{y}^{\prime}=0 \quad \text { at } \eta=1
\end{aligned}
$$

The solution of the equation (1) is

$$
\tilde{y}(\eta)=\frac{\psi_{2}(1) \psi_{1}(\eta)-\psi_{1}(1) \psi_{2}(\eta)}{\lambda_{1}\left(1+\lambda_{1}^{2} \lambda_{2}^{-2}\right) \psi_{1}(1)}
$$

Here

$$
\begin{aligned}
& \psi_{1}(\eta)=\cosh \left(\lambda_{1} \eta\right)+\lambda_{1}^{2} \lambda_{2}^{-2} \cos \left(\lambda_{2} \eta\right) \\
& \psi_{2}(\eta)=\sinh \left(\lambda_{1} \eta\right)+\lambda_{1}^{3} \lambda_{2}^{-3} \sin \left(\lambda_{2} \eta\right) \\
& \lambda_{1}=\sqrt{-0.5 \lambda+\sqrt{\omega^{2}+0.25 \lambda^{2}}} \\
& \lambda_{2}=\sqrt{0.5 \lambda+\sqrt{\omega^{2}+0.25 \lambda^{2}}}
\end{aligned}
$$

The transcendental equation relating the load parameter $(\lambda)$ and the frequency parameter $(\omega)$ is in the form $\lambda^{2}+2 \omega^{2}\left(1+\cosh \lambda_{1} \cos \lambda_{2}\right)+\lambda \omega \sinh \lambda_{1} \sin \lambda_{2}=0$

Equation (9) is solved for the frequency parameter $(\omega)$ by specifying the load parameter $(\lambda)$ using the Mathematica ${ }^{\circledR}$.
From equation (4), one can find that

$$
\frac{\delta}{L}=\tilde{y}(0)=\frac{\psi_{2}(1)}{\lambda_{1} \psi_{1}(1)}
$$

Stability of the column is assessed from the load versus frequency curve (which is nothing but the eigencurve). Critical load is the minimum load at which the eigencurve cuts the load axis. The dynamic stability load is the minimum load where two branches of eigencurve coalesce. To generate the eigencurves from the first two frequency parameters $\left(\omega_{1}\right.$ and $\left.\omega_{2}\right)$ specifying the load parameter $(\lambda)$, the procedure is as follows. By setting $\lambda=0, \omega_{1}$ and $\omega_{2}$ are found for the unloaded column from equation (9). The eigencurves are generated considering the first two frequencies by specifying the values of $\lambda$ varying from 0 in steps of 1 . It is observed that when $\lambda$ value is reached to 21 , Mathematica ${ }^{\circledR}$ provides bifurcated frequency values. Each time, the step size is reduced to half for obtaining the frequency values prior to the bifurcation load parameter. At $\lambda_{c}=20.0509$, the two positive frequency values are tending to the coalescing frequency parameter $\left(\omega_{c}\right)$ value of 11.011 .

Xiong et al. [27] have considered a centripetally loaded model and simulated Beck's column showing equivalence of the first and second modes individually. The centripetal load is applied to three aluminum specimens (having Young's modulus $=69.8 \mathrm{GPa}$ and mass density, $\rho=2800 \mathrm{~kg} / \mathrm{m}^{3}$ ) by means of thin steel wires passing through a fixed point at a distance from free end. The present analysis results in Figures 2 to 4 are reasonably in good agreement with measured vibration frequencies [27]. Xiong et al. [27] have not conducted experiments up to stability load. They have employed a curve-fitting procedure for the measured data relevant to the load parameter $\lambda$ and the frequency parameter $\omega$. The stability load of Beck's column estimated from the fitted curve is found to be below $10 \%$ of the theoretical values. It should be noted that the discrepancy between dynamic analysis results and test data can be expected mainly due to the assigned values of the Young's modulus and mass density of the material. The characteristic equation of Beck's column should not be adjusted to account the discrepancies as being done in [27].
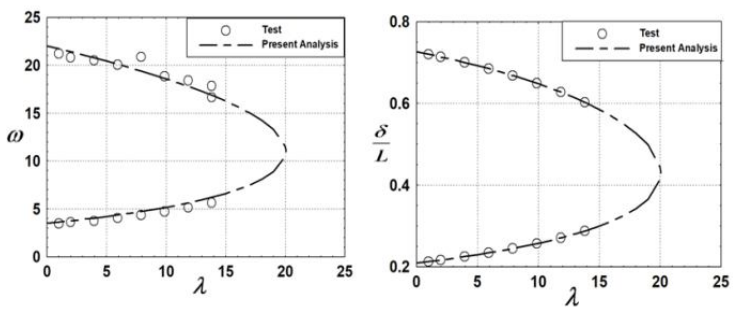

Figure 2: Comparison of analysis results and experimental results of Xiong et al. [27] for the aluminum column of size $299.94 \times 10.21 \times 2.85 \mathrm{~mm}$ 

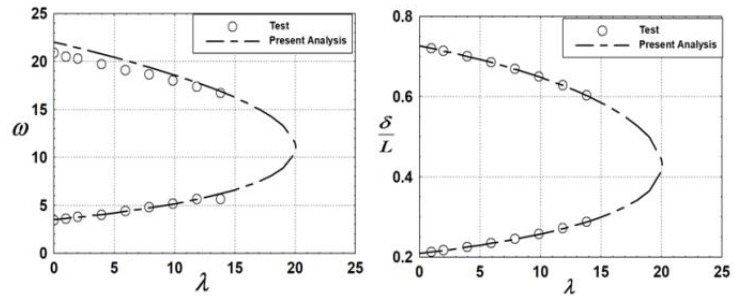

Figure 3: Comparison of analysis results and experimental results of Xiong et al. [27] for the aluminum column of size $300.1 \times 10.11 \times 2.92 \mathrm{~mm}$
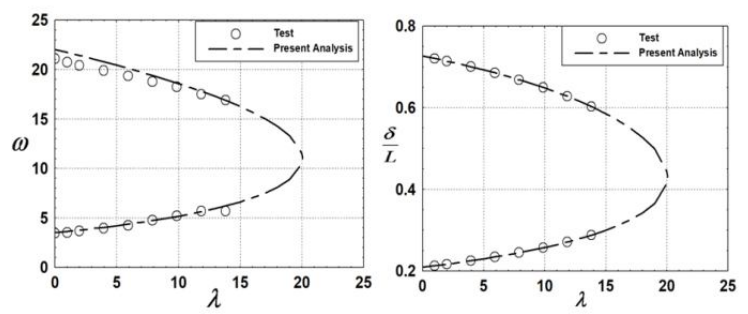

Figure4: Comparison of analysis results and experimental results of Xiong et al. [27] for the aluminum column of size $300.34 \times 10.29 \times 2.87 \mathrm{~mm}$

\section{CONCLUSION}

A centripetally loaded model of Xiong et al. [27] and their simulations on Beck's column show equivalence of the first and second modes individually. They have analyzed the dynamic characteristics of Beck column and a centripetally loaded column. This article demonstrates their equivalence directly from the dynamic characteristics of Beck column. Test results of Xiong et al. [27] match well with the present analysis results. Xiong et al. [27] have not conducted experiments up to stability load. Instead of correcting the Young's modulus and the density of the column material, they have wrongly updated the characteristic equation of the Beck column employing a curve-fitting procedure for the measured load parameter $(\lambda)$ and the frequency parameter $(\omega)$.

\section{REFERENCES}

1. S.P. Timoshenko and J.M. Gere, "Theory of Elastic Stability", Tata McGraw-Hill Education Private Limited, New Delhi , 2012.

2. M.A. Langthjem and Y. Sugiyama, "Optimum design of cantilevered columns under the combined action of conservative and non-conservative loads, Part-I: The undamped case", Computers and Structures, Vol.74, pp.385-398, 2000.

3. M.A. Langthjem and Y. Sugiyama, "Dynamic stability of columns subjected to follower loads: a survey", Journal of Sound and Vibration, Vol.238, pp. 809-851, 2000.

4. S.B. Anderson and J.J. Thomsen, "Post-critical Behavior of Beck's column with a tip mass", International Journal of Nonlinear Mechanics, Vol.37, pp.135-151, 2002.

5. Yu.V. Zahharov, K.G. Okhotkin and A.D. Skorobogatov, "Bending of bars under a follower
Load “, Journal of Applied Mechanics and Technical Physics, Vol.45, pp.756-763, 2004.

6. I. Elishakoff, "Controversy associated with the socalled 'Follower Forces': critical Overview", Applied Mechanics Reviews, Vol.58, pp.1171422005.

7. L. Kwasniewsi, "Numerical verification of postCritical Beck's column behavior", International Journal of Nonlinear Mechanics, Vol.45, pp.242-255, 2010.

8. B. Nageswara Rao and G. Venkateswara Rao, "Postcritical behaviour of a uniform cantilever column under a tip concentrated follower force", J. Sound and Vibration, Vol.132, pp.350-352, 1989.

9. B. Nageswara Rao and G. Venkateswara Rao, "Some studies on buckling and post- buckling of cantilever columns subjected to conservative or non conservative loads", The Journal of the Aeronautical Society of India, Vol.41, No.2, pp.165-182, 1989.

10. B. Nageswara Rao and G. Venkateswara Rao, "Stability of tapered cantilever columns subjected to a tip concentrated sub tangential follower force", Forschung Im Ingenieurwesen, Vol.56, No.3, pp.9396,1990.

11.B. Nageswara Rao and G. Venkateswara Rao, "Postcritical behaviour of a tapered cantilever column subjected to a tip concentrated follower force", $Z$. angew. Math. Mech. (ZAMM), Vol.71, pp.471-473 1991.

12. B.P. Madhusudan, V.R. Rajeev and B. Nageswara Rao, "Post-buckling of cantilever columns having variable cross-section under a combined load", Int. J. Non-linear Mechanics, Vol.38, pp.1513-1522 2003.

13. M. Mutyalarao, D. Bharathi and B. Nageswara Rao, "Dynamic stability of cantilever columns under a tip- concentrated sub tangential follower force", Mathematics and Mechanics of Solids, Vol.18, No.5, pp.449-463 2012.

14. N. Willems, "Experimental verification of the dynamic stability of a tangentially loaded cantilever column", Transactions of ASME Journal of Applied Mechanics, Vol.33, pp.460-461 .1966.

15. N.C. Huang, W. Nachabar and S. Nemat-Nasser, "On Willems' experimental verification of the critical load in Beck's problem", Transactions of ASME Journal of Applied Mechanics, Vol.34, pp.243-245 1967.

16. Discussion by G. Augusti, J. Roorda, G. Herrmann and M. Levinson, "Experimental verification of the dynamic stability of a tangentially cantilever column", Transactions of ASME Journal of Applied Mechanics, Vol.34, pp.523-524 1967.

17. W.T. Koiter, "Unrealistic follower forces", Journal of Sound and Vibration, Vol.194.No.4, pp.636-638 (1996)

18. Y. Sugiyama, M.A. Langthjem and B.J. Ryu, "Realistic follower forces", Journal of Sound and Vibration, Vol.225, pp.779-782 (1998)

19. I. Mascolo, "Recent developments in the dynamic Stability of elastic structures", Frontiers in Applied Mathematics and Statistics, Vol.5, Article.51 (2019) 16 pages doi:10.3389/fams.2019.00051 
20.I. Elishakoff, "Essay on the contributors to the elastic stability theory", Meccanica, Vol.40, pp.75110 (2005)

21. V.V. Bolotin, "Non-conservative problems of the theory of elastic stability", Macmillan, New York (1963)

22. M. Kh. Mullagulov, "Experimental-Theoretical Study of the Stability of Rods, Compressed by Follower Forces", Strength of Materials, Vol.26, No.6, pp.441- 446.1994.

23. Y. Sugiyama, K. Katayama and K. Kiriyama, "Experimental verification of dynamic stability of vertical cantilever columns subjected to a sub tangential force", Journal of Sound and Vibration, Vol.236, No.2, pp.193-207 (2000)

24. Y. Sugiyama, "Experimental approach to non conservative stability problems", In: Modern problems of structural Stability' (Edited by Alexander P. Seyranian and Isaac Elishakoff), CISM International Centre for Mechanical Science Series Vol. 436, Springer-Verlag Wien (2002), DOI: 10.1007/978-3-7091-2560-1

25. Y. Sugiyama, M.A. Langthjem and K. Katayama, "Dynamic Stability of Columns under Nonconservative Forces: Theory and Experiments', Solid Mechanics and its Applications, Vol.255, Springer Nature Switzerland AG (2019) DOI: 10.1007/978-3- 030-00572-6

26. M. Mutyalarao, D. Bharathi, K.L. Narayana and B. Nageswara Rao, "How valid are Sugiyama's experiments on follower forces?", International journal of Non-linear Mechanics, Vol.93, pp. 1221252017.

27. Y. Xiong, T.K. Wang and B. Tabarrok, "On a centripetally loaded model simulating Beck's column", International Journal of Solids and Structures, Vol.25, No.10, pp.1107-1113 (1989)

28. J. Peter Praveen, R. Donthi, S.V.Prasad, B. Mahaboob, B.Venkateswarlu B., A glance on the estimation of Cobb-Douglas production functional model, AIP Conference Proceedings, 2177 (1), 020067. 2019

29. J.Peter Praveen, B. Mahaboob, R.Donthi, S.V. Prasad, B.Venkateswarlu, On stochastic linear regression model selection, AIP Conference Proceedings, 2177 (1), 020068, 2019.

30. B.Mahaboob, J.Peter Praveen, R.Donthi, S.V.Prasad, B.Venkateswarlu B., Criteria for selection of stochastic linear model selection, AIP Conference Proceedings, 2177 (1), 020041,2019.

31. R.Donthi, S.V.Prasad, B.Mahaboob, J.Peter Praveen, B.Venkateswarlu. Estimation methods of nonlinear regression models, AIP Conference Proceedings, 2177 (1), 020081, 2019.

32. R.Donthi, J.Peter Praveen, S.V.Prasad, B.Mahaboob, B.Venkateswarlu, Numerical techniques of nonlinear regression model estimation, AIP Conference Proceedings, 2177 (1), 020082. 2019.

33. B.Mahaboob, S.V.Prasad, J.Peter Praveen, R.Donthi, B.Venkateswarlu, On misspecification tests for stochastic linear regression model, AIP Conference Proceedings, 2177 (1), 020039. 2019.
34. B.Mahaboob, Ajmath K.A., Venkateswarlu B., Narayana C., Praveen J.P. ,On Cobb-Douglas production function model, AIP Conference Proceedings, 2177 (1), 020040. 2019.

35. B.Mahaboob, K.A.Azmath, B.Venkateswarlu, C.Narayana, B.M.Rao An evaluation in generalized LSE of linearized stochastic statistical model with non-spherical errors, AIP Conference Proceedings, 2177(1), 020038. 2019.

36. Mahaboob B., Venkateswarlu B., Azmath K.A., Narayana C., Peter Praveen J. 'On OLS estimation of stochastic linear regression model', International Journal of Engineering and Advanced Technology, 8(6), pp.1953-1955, 2019.

37. B.Venkateswarlu , B.Mahaboob B., K.A.Azmath ,C.Narayana.,C.Muralidaran, 'An application of linear programming in the estimation of technical efficiency of DMU', International Journal of Engineering and Advanced Technology, 8(6), pp.1956-1959, 2019.

38. Aaron Don M. Africa, Samuel Alexander Pasia, Jereme Adriane Sy,, "A Modeling system on the Implementation of Automated Vehicles", International Journal of Emerging Trends in Engineering Research,Vol. 8(7),pp.2923-2926. 2020.

39. P. S. Ramesh, S. Arivalagan, P. Sudhakar, “Automated Prognostic Modelling of Alzheimer's Disease Prediction based on Machine Learning over Brain Networks", International Journal of Emerging Trends in Engineering Research, Vol. 8(7),pp.2963-2971, 2020.

40. J. Peter Praveen, B. Nageswara Rao, Y. Harnath, B.V. Appa Rao, C. Narayana, and B. Mahaboob, "Existence of solution of the nonlinear differential equation in the modelling of eardrum by using homotopy perturbation method", Advances in Mathematics: Scientific Journal, Vol.9, No.7, pp.4853-4862,2020.

41. B. Mahaboob., J.P.Praveen, B.V.Appa Rao, Y.Harnath ,C. Narayana,G.B. Prakash, , "A study on multiple linear regression using matrix calculus" Advances in Mathematics: Scientific Journal, Vol.9, No.7, pp.4863-4872, 2020. 